\title{
The Reliability Evaluation Method of Software and Hardware Integrated Systems Based on Belief Reliability
}

\author{
Xuan Hu, Jie Liu ${ }^{+}$ \\ Information Security Research Center, CEPREI, \\ Key laboratory of Ministry of Industry and Information Technology, China
}

\begin{abstract}
Existing software and hardware integrated systems reliability evaluation methods ignore the problem of different failure mechanisms of hardware and software; thus, there are some limitations. In view of the above problems, this paper firstly studies time/state-based failure. Moreover, for the problem of reliability measurement in the presence of epistemic uncertainty, a calculation method of epistemic uncertainty factor of software and hardware integrated systems based on failure mode and effect analysis application effect and software and hardware comprehensive reliability test application effect is proposed. Furthermore, a belief reliability evaluation method with comprehensive consideration of design margin, aleatory uncertainty and epistemic uncertainty is presented. Finally, the proposed method is demonstrated and verified through application case. The results show that the existence of epistemic uncertainty will reduce people's trust in "system reliability".
\end{abstract}

Keywords: software and hardware integrated systems, belief reliability, failure mode and effect analysis, epistemic uncertainty

\section{Introduction}

A system based on microelectronics technology and embedded software that implements information sharing, system integration, and intelligent control is called a software and hardware integrated systems (S/HIS). Examples include embedded systems for automotive and avionics applications, telecommunications, wireless ad hoc systems, business applications with an emphasis on web services, etc [1]. However, since the interaction between hardware and software in this type of system [2, 3], to accurately evaluate its reliability, a systematic evaluation method must be established from the perspective of software and hardware integration.

The initial research on the reliability evaluation of S/HIS mainly focused on evaluating the reliability of software and hardware separately. The main task of this was to combine and match various models ${ }^{[4-7]}$. However, this method did not solve the problem of different hardware and software failure mechanisms. The traditional reliability theory based on probability statistics did not pay attention to the deterministic causes of the system failure; instead, it used statistical methods to analyze the overall reliability level of system. Yet, the limitations of traditional reliability theory of ex post facto feedback had become increasingly prominent. In this case, a reliability theory based on Physics-of-Failure (PoF) has emerged [8], using failure mechanism models to describe the deterministic laws of failures, and using the variability of model parameters to characterize the effects of uncertain factors. However, the variability of model parameters described only aleatory uncertainty (AU). It did not consider the uncertainty of the accuracy of failure mechanism and the selected model, which is affected by the cognitive state of analyst. Obviously, it is necessary to fully consider epistemic uncertainty (EU) to obtain the accurate reliability evaluation results of a S/HIS. In 1990, Apostolakis G, wrote in Science that in addition to the uncertainty of model parameters, there is also

\footnotetext{
+ Corresponding author. Tel.: + 13671022268; fax: +020-87238359.
}

E-mail address: 47507346@qq.com. 
uncertainty in the model itself caused by incomplete knowledge of the modeler [9], i.e., the EU. In contrast, the uncertainty inherent in the objective world is called AU [10,11]. Actually, the failure law of system is affected by deterministic causes, AU and EU. Based on this understanding, literature [12] proposed a reliability measure index called belief reliability (BR) that considers the effects of design margin (DM), AU, and EU. Literature [13] further gave the calculation method of the BR and the influence of EU on system reliability quantitatively expressed by the parameter "EU factor". In engineering, a large part of reliabilityrelated engineering activities is aimed at reducing the impact of EU, e.g., performing failure mode and effect analysis (FMEA) [14]. For S/HIS, if not only the effect of hardware failures is considered in the FMEA process, but also the effect of software and hardware comprehensive failures can be fully considered, which can further reduce the EU. Besides, an important type of failure in S/HIS, the time/state-based (TS-based) failure [15], has increasingly become an important factor that plagues developers and users and greatly affects the reliability level of S/HIS. The direct cause of this type of failure is generally unforeseen changes in operating conditions or environmental conditions associated with S/HIS. Therefore, the development of software and hardware comprehensive reliability test (S/HCRT) for such failure will also affect the EU of the system. In summary, the value of the EU factor can be determined based on the results of the above two types of activities.

This paper firstly studied the mechanism of TS-based failure, and presented two kinds of failure mechanism models. Secondly, based on the method proposed in $[12,13,16]$, by adding the content related to the TS-based failure during the implementation of FMEA which can determine the first type of EU factor, the EU factor related to the FMEA of the S/HIS can be obtained. Thirdly, based on the second type of EU factor determination method, i.e., S/HCRT, the EU factor related to the S/HCRT can be obtained. These two types of EU factors are further integrated. Finally, considering the DM of the performance parameters of the $\mathrm{S} / \mathrm{HIS}$ and the influence of the AU factor, the BR of the S/HIS is given.

\section{The TS-based Failure of S/HIS}

Definition In some cases, unpredictable operations and stresses with physical, chemical or other characteristics act on the hardware part of system directly, further directly or indirectly cause abnormal software operation, and then react to components or systems, which then causes the system behavior to be inconsistent with expectations. The occurrence of a failure has corresponding consequences and can be corrected by some means.

From the above definition, it can be known that the root cause of the TS-based failure is generally the unpredictable changes in operating conditions or environmental conditions, e.g., the SEFI of the single event effect, i.e., the digital logic components lose their original functions under the bombardment of a single charged particle. When a single heavy ion hits an integrated circuit chip, the deposited local dose can damage the silicon region of a channel length range of a MOS tube, resulting in a fixed electrical state. When the running software program reads the above-mentioned fixed-bit values, these values can no longer be read out correctly, leading to catastrophic consequences. Fig. 1 shows the life cycle of the TS-based failure.

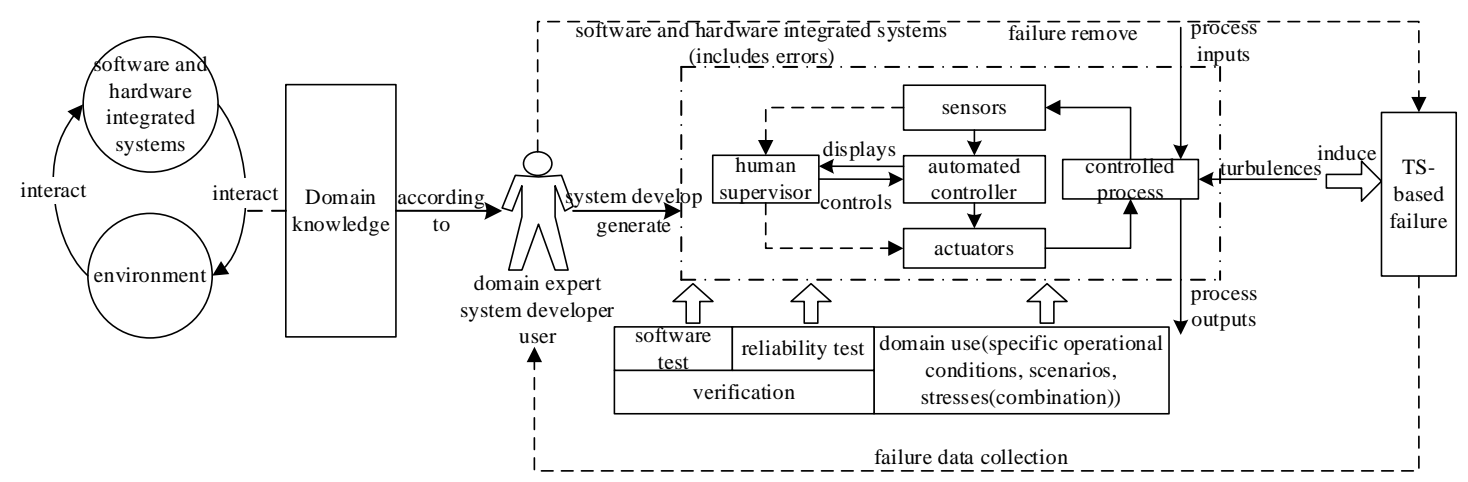

Fig. 1: The life cycle of the TS-based failure 
As can be seen from Fig. 1, the failure mechanism of the TS-based failure is very different from the simple hardware or software failure mechanism. The hardware failure is usually triggered by certain stress type and stress level over time; the software failure is usually caused by certain operating conditions, depending on whether the code containing the software error is run, thus it is space-based and theoretically independent of time. However, the TS-based failure is related to both time and space.

Nowadays, almost all failure mechanism analysis of engineering systems is based on the causal chain or tree model of failure events, which can only describe the direct and linear relationship between events. It is therefore impossible to characterize the TS-based failures caused by environmental disturbances that occur over time. To overcome the deficiency, it is necessary to use the model which is based on cybernetics and can describe indirect, non-linear relationships and state transitions. And it can characterize the TS-based failures caused by environmental disturbances that occur over time.

\section{The Definition of BR}

The BR is a kind of reliability metric suitable for describing the failure laws of systems under the combination of aleatory and EU. It is defined as ${ }^{[13]}$,

$$
\begin{gathered}
\mathrm{R}_{\mathrm{B}}=\Phi\left(\mathrm{M}_{\mathrm{d}} /\left(\mathrm{U}_{\mathrm{a}}+\mathrm{U}_{\mathrm{e}}\right)\right) \\
\Phi(\mathrm{x})=(1 / \sqrt{2 \pi}) \int_{-\infty}^{\mathrm{x}} \exp \left(-\mathrm{t}^{2} / 2\right) \mathrm{dt}
\end{gathered}
$$

where, $M_{d}$ is the DM (the average of system performance margin distribution), $-\infty<M_{d}<+\infty$. It is a representation of the deterministic cause of failure. $U_{a}$ represents the AU which is used to characterize the impact of AU on system reliability. $U_{a} \geqslant 0$. Generally, the $U_{a}$ is measured by the standard deviation of the performance margin distribution. $U_{e}$ represents the EU, which is used to characterize the impact of EU on system reliability. $U_{e} \geqslant 0$. The $U_{e}$ can be determined by evaluating the application effects of engineering activities related to the EU. To facilitate the calculation, the AU and EU of the performance margin are usually normalized, and the AU factor $\alpha_{a}$ and EU factor $\alpha_{\varepsilon}$ are defined as,

$$
\begin{gathered}
\alpha_{a}=U_{a} /\left|M_{d}\right| \geq 0 \\
\alpha_{e}=U_{e} /\left|M_{d}\right| \geq 0
\end{gathered}
$$

then the BR can be calculated according to the following equation,

$$
R=\left\{\begin{array}{c}
\Phi\left(1 /\left(\alpha_{a}+\alpha_{e}\right)\right), M_{d} \geq 0 \\
1-\Phi\left(1 /\left(\alpha_{a}+\alpha_{e}\right)\right), M_{d}<0
\end{array}\right.
$$

\section{The Determining of EU Factor Of S/HIS}

\subsection{The Evaluation Method of FMEA Application Effect}

The variable $\mathrm{E}$ is defined to characterize the application effect of FMEA. Regulation: The larger the E, the better the application effect of FMEA. The main factors affecting $E$ are divided into the following four aspects ${ }^{[16]}$, the degree of failure mode cognition, cause cognition, effect cognition, and the effectiveness of

\begin{tabular}{|c|c|c|c|c|}
\hline \multirow[t]{2}{*}{ Effect factor } & \multicolumn{2}{|c|}{ Evaluation criteria } & \multirow{2}{*}{\multicolumn{2}{|c|}{ Scoring criteria }} \\
\hline & $\begin{array}{l}\text { Evaluation } \\
\text { point }\end{array}$ & $\begin{array}{l}\text { Evaluation } \\
\text { requirement }\end{array}$ & & \\
\hline \multirow{5}{*}{$\begin{array}{l}\text { the degree of } \\
\text { failure mode } \\
\text { cognition } \mathrm{E}_{1}\end{array}$} & \multirow{5}{*}{$\begin{array}{l}\text { the quality of } \\
\text { failure } \\
\text { criterion } \\
\text { definition } \mathrm{E}_{11}\end{array}$} & \multirow{3}{*}{$\begin{array}{l}E_{111} \text { the } \\
\text { definition of } \\
\text { failure criteria } \\
\text { is clear }\end{array}$} & $\begin{array}{l}\text { can very clearly determine whether the system has } \\
\text { failed according to the failure criteria }\end{array}$ & $E_{111}=3$ \\
\hline & & & $\begin{array}{l}\text { can clearly determine whether the system has failed } \\
\text { according to the failure criteria }\end{array}$ & $\mathrm{E}_{111}=1$ \\
\hline & & & $\begin{array}{l}\text { cannot clearly determine whether the system has failed } \\
\text { according to the failure criteria }\end{array}$ & $\mathrm{E}_{111}=0$ \\
\hline & & \multirow{2}{*}{$\begin{array}{l}\mathrm{E}_{112} \text { the } \\
\text { definition of } \\
\text { failure criteria } \\
\text { is complete }\end{array}$} & $\begin{array}{l}\text { failure criteria can support a very comprehensive } \\
\text { analysis of failure modes, considering the hardware } \\
\text { and software factors }\end{array}$ & $\mathrm{E}_{112}=3$ \\
\hline & & & failure criteria can support a comprehensive analysis of & $E_{112}=1$ \\
\hline
\end{tabular}
improvement measures. Evaluation criteria are established for each aspect to evaluate the influence of these factors on $\mathrm{E}$, as shown in Tab. $1 . \mathrm{E}_{1} \sim \mathrm{E}_{4}$ in Tab. 1 respectively reflects the above four aspects, and $E_{i} \in[0,1], i=1,2,3,4$, Regulation: The closer the $\mathrm{E}_{\mathrm{i}}$ is to 1 , the better the completion of this aspect is.

Table.1: The evaluation criteria of the FMEA application effect of S/HIS 


\begin{tabular}{|c|c|c|c|c|}
\hline & & & $\begin{array}{l}\text { failure modes, considering the traditional hardware } \\
\text { factor only }\end{array}$ & \\
\hline & & & $\begin{array}{l}\text { failure criteria cannot support comprehensive analysis } \\
\text { of failure modes }\end{array}$ & $E_{112}=0$ \\
\hline & $\begin{array}{l}\text { the } \\
\text { completeness }\end{array}$ & $\begin{array}{l}\mathrm{E}_{121} \text { the failure } \\
\text { mode analysis }\end{array}$ & $\begin{array}{lllll}\text { expert review confirms } & \text { functional } & \text { coverage is } \\
\text { complete }\end{array}$ & $E_{121}=3$ \\
\hline & & & $\begin{array}{l}\text { expert review finds that some non-critical functions are } \\
\text { missing }\end{array}$ & $\mathrm{E}_{121}=1$ \\
\hline & analysis $\mathrm{E}_{12}$ & $\begin{array}{l}\text { that the system } \\
\text { needs to } \\
\text { complete }\end{array}$ & $\begin{array}{l}\text { expert review finds that a large number of critical } \\
\text { functions are missing }\end{array}$ & $\mathrm{E}_{121}=0$ \\
\hline & & $\begin{array}{l}\mathrm{E}_{122} \text { the failure } \\
\text { mode analysis } \\
\text { should cover } \\
\text { the various use } \\
\text { and } \\
\text { environmental } \\
\text { conditions that }\end{array}$ & $\begin{array}{l}\text { expert review confirms that the coverage of use and } \\
\text { environmental conditions is complete. The meaning of } \\
\text { "completeness" here includes not only the traditional } \\
\text { use and environmental conditions, but also the } \\
\text { operating conditions and use environments } \\
\text { corresponding to the TS-based failure, i.e., the software } \\
\text { factor needs to be considered }\end{array}$ & $E_{122}=3$ \\
\hline & & $\begin{array}{l}\text { the system may } \\
\text { experience }\end{array}$ & $\begin{array}{l}\text { expert review confirms the coverage of traditional use } \\
\text { and environmental conditions related to failure is } \\
\text { complete, yet the operational and environmental } \\
\text { conditions of TS-based failure not considered, i.e., the } \\
\text { software factor not considered }\end{array}$ & $E_{122}=1$ \\
\hline & & & $\begin{array}{l}\text { expert review confirms the traditional use and } \\
\text { environmental conditions related to failure is partly } \\
\text { considered, yet the operational and environmental } \\
\text { conditions of TS-based failure not considered, i.e., the } \\
\text { software factor not considered }\end{array}$ & $\mathrm{E}_{122}=0.6$ \\
\hline & & & $\begin{array}{l}\text { expert review confirms that a large number of } \\
\text { traditional use and environmental conditions related to } \\
\text { failure not considered, and the operational and } \\
\text { environmental conditions corresponding to TS-based } \\
\text { failure not considered }\end{array}$ & $\mathrm{E}_{122}=0$ \\
\hline & & $\begin{array}{ll}E_{123} \text { the } & \text { failure } \\
\text { mode } & \text { should }\end{array}$ & $\begin{array}{l}\text { the loss of function and degraded function are both } \\
\text { considered }\end{array}$ & $E_{123}=3$ \\
\hline & & include & only one type of failure mode is analyzed & $E_{123}=1$ \\
\hline & & $\begin{array}{l}\text { complete loss of } \\
\text { function and } \\
\text { degraded } \\
\text { function }\end{array}$ & neither type of failure mode is analyzed & $E_{123}=0$ \\
\hline & $\begin{array}{l}\text { the trust } \\
\text { degree of }\end{array}$ & $\begin{array}{l}\mathrm{E}_{131} \text { the failure } \\
\text { modes }\end{array}$ & $\begin{array}{l}\text { the failure mode is derived from the historical data of } \\
\text { this system or similar system }\end{array}$ & $\mathrm{E}_{131}=3$ \\
\hline & $\begin{array}{l}\text { failure mode } \\
\text { source } \mathrm{E}_{13}\end{array}$ & & $\begin{array}{l}\text { the failure mode is derived from authoritative } \\
\text { literature, standards, manuals }\end{array}$ & $\mathrm{E}_{131}=1$ \\
\hline & & $\begin{array}{l}\text { should have a } \\
\text { trusted source }\end{array}$ & the failure mode is derived from experts' experiences & $E_{131}=0$ \\
\hline $\begin{array}{l}\text { the degree of } \\
\text { failure cause } \\
\text { cognition } E_{2}\end{array}$ & $\begin{array}{l}\text { the } \\
\text { completeness } \\
\text { of failure }\end{array}$ & $\begin{array}{l}\mathrm{E}_{211} \text { the failure } \\
\text { causes } \\
\text { considered in }\end{array}$ & $\begin{array}{l}\text { expert review confirms the cause coverage is complete } \\
\text { and comprehensively considers the hardware and } \\
\text { software factors }\end{array}$ & $E_{211}=3$ \\
\hline & $\begin{array}{l}\text { cause } \\
\text { analysis } \mathrm{E}_{21}\end{array}$ & $\begin{array}{l}\text { the analysis } \\
\text { should cover all } \\
\text { possible } \\
\text { situations }\end{array}$ & $\begin{array}{l}\text { expert review confirms the comprehensive coverage of } \\
\text { hardware failure causes; yet, failure causes } \\
\text { corresponding to the failure mechanism model of the } \\
\text { S/HIS not considered }\end{array}$ & $\mathrm{E}_{211}=1$ \\
\hline & & & $\begin{array}{l}\text { expert review confirms that some non-critical hardware } \\
\text { failure causes are missing, and the failure causes } \\
\text { corresponding to the S/HIS failure mechanism model } \\
\text { not considered }\end{array}$ & $E_{211}=0.6$ \\
\hline & & & $\begin{array}{l}\text { expert review confirms that a large number of critical } \\
\text { failure causes are missing }\end{array}$ & $\mathrm{E}_{211}=0$ \\
\hline & $\begin{array}{l}\text { the } \\
\text { completeness } \\
\text { of }\end{array}$ & $\begin{array}{l}\mathrm{E}_{221} \text { the failure } \\
\text { transitivity } \\
\text { analysis should }\end{array}$ & $\begin{array}{l}\text { The horizontal and vertical transitivities are fully } \\
\text { analyzed. The vertical transitivity refers to the effect of } \\
\text { failures on the previous level; the horizontal }\end{array}$ & $E_{221}=3$ \\
\hline
\end{tabular}




\begin{tabular}{|c|c|c|c|c|}
\hline & $\begin{array}{l}\text { transitivity } \\
\text { analysis } \mathrm{E}_{22}\end{array}$ & $\begin{array}{l}\text { include vertical } \\
\text { and horizontal }\end{array}$ & $\begin{array}{l}\text { transitivity refers to the failure transitivity between } \\
\text { products at the same level }\end{array}$ & \\
\hline & & transitivity & Considering vertical transitivity only & $E_{221}=1$ \\
\hline & & analysis & No transitivity analysis is conducted & $E_{221}=0$ \\
\hline $\begin{array}{l}\text { the degree of } \\
\text { failure effect }\end{array}$ & $\begin{array}{l}\text { the } \\
\text { completeness }\end{array}$ & $\begin{array}{l}E_{311} \text { failure } \\
\text { effect analysis }\end{array}$ & $\begin{array}{l}\text { expert review confirms that failure effect analysis is } \\
\text { complete }\end{array}$ & $E_{311}=3$ \\
\hline cognition $E_{3}$ & $\begin{array}{l}\text { of failure } \\
\text { effect }\end{array}$ & $\begin{array}{l}\text { should cover } \\
\text { local effect, }\end{array}$ & $\begin{array}{l}\text { expert review confirms that some of failure effect is } \\
\text { missing }\end{array}$ & $E_{311}=1$ \\
\hline & analysis $\mathrm{E}_{31}$ & $\begin{array}{l}\text { previous level } \\
\text { effect and final } \\
\text { effect }\end{array}$ & $\begin{array}{l}\text { expert review confirms that a large number of failure } \\
\text { effect is missing }\end{array}$ & $E_{311}=0$ \\
\hline & $E_{32}$ the & $\mathrm{E}_{321}$ the data & derived from actual data & $E_{321}=3$ \\
\hline & $\begin{array}{l}\text { accuracy of } \\
\text { criticality }\end{array}$ & $\begin{array}{l}\text { source of } \\
\text { criticality }\end{array}$ & $\begin{array}{l}\text { derived from authoritative literature or standards, } \\
\text { manuals }\end{array}$ & $E_{321}=1$ \\
\hline & analysis & $\begin{array}{l}\text { analysis should } \\
\text { be reasonable } \\
\text { and credible }\end{array}$ & derived from experts' experiences & $\mathrm{E}_{321}=0$ \\
\hline & & $\mathrm{E}_{322}$ the method & adopt the improved criticality analysis methods & $E_{322}=3$ \\
\hline & & $\begin{array}{l}\text { of criticality } \\
\text { analysis should } \\
\text { be reasonable }\end{array}$ & $\begin{array}{l}\text { adopt the traditional criticality analysis method, i.e., } \\
\text { RPN }\end{array}$ & $E_{322}=0$ \\
\hline $\begin{array}{l}\text { the } \\
\text { effectiveness } \\
\text { of } \\
\text { improvement }\end{array}$ & $\begin{array}{l}E_{41} \text { the } \\
\text { extent to } \\
\text { which the } \\
\text { failure mode }\end{array}$ & $\begin{array}{l}\mathrm{E}_{411} \text { the } \\
\text { improvement } \\
\text { measures can } \\
\text { eliminate the }\end{array}$ & $\begin{array}{l}\text { After expert review, all the analyzed failure modes } \\
\text { have been improved, including hardware failure modes } \\
\text { and software and hardware comprehensive failure } \\
\text { modes }\end{array}$ & $\mathrm{E}_{411}=3$ \\
\hline measures $\mathrm{E}_{4}$ & $\begin{array}{l}\text { has been } \\
\text { eliminated }\end{array}$ & $\begin{array}{l}\text { failure modes } \\
\text { analyzed or } \\
\text { reduce the }\end{array}$ & $\begin{array}{l}\text { After expert review, all the hardware failure modes } \\
\text { have been improved, but the software and hardware } \\
\text { comprehensive failure modes have not been improved }\end{array}$ & $\mathrm{E}_{411}=1$ \\
\hline & & $\begin{array}{l}\text { probability of } \\
\text { happening } \\
\text { without }\end{array}$ & $\begin{array}{l}\text { After expert review, some hardware failure modes have } \\
\text { been improved, but software and hardware } \\
\text { comprehensive failure modes have not been improved }\end{array}$ & $\mathrm{E}_{411}=0.6$ \\
\hline & & $\begin{array}{l}\text { introducing new } \\
\text { failures }\end{array}$ & $\begin{array}{l}\text { After expert review, a large number of hardware failure } \\
\text { modes and software and hardware comprehensive } \\
\text { failure modes have not been improved }\end{array}$ & $\mathrm{E}_{411}=0$ \\
\hline & $\begin{array}{l}E_{42} \text { the } \\
\text { extent to } \\
\text { which the } \\
\text { failure cause }\end{array}$ & $\begin{array}{l}\mathrm{E}_{421} \text { the } \\
\text { improvement } \\
\text { measures can } \\
\text { eliminate the }\end{array}$ & $\begin{array}{l}\text { After expert review, all the analyzed failure causes } \\
\text { have been improved, including hardware failure causes } \\
\text { and software and hardware comprehensive failure } \\
\text { causes }\end{array}$ & $\mathrm{E}_{421}=3$ \\
\hline & $\begin{array}{l}\text { has been } \\
\text { eliminated }\end{array}$ & $\begin{array}{l}\text { failure causes } \\
\text { analyzed or } \\
\text { reduce the }\end{array}$ & $\begin{array}{l}\text { After expert review, all the hardware failure causes } \\
\text { have been improved, but the software and hardware } \\
\text { comprehensive failure causes have not been improved }\end{array}$ & $\mathrm{E}_{421}=1$ \\
\hline & & $\begin{array}{l}\text { probability of } \\
\text { happening } \\
\text { without }\end{array}$ & $\begin{array}{l}\text { After expert review, some hardware failure causes have } \\
\text { been improved, but software and hardware } \\
\text { comprehensive failure causes have not been improved }\end{array}$ & $\mathrm{E}_{421}=0.6$ \\
\hline & & $\begin{array}{l}\text { introducing new } \\
\text { failures }\end{array}$ & $\begin{array}{l}\text { After expert review, a large number of hardware failure } \\
\text { causes and software and hardware comprehensive } \\
\text { failure causes have not been improved }\end{array}$ & $\mathrm{E}_{421}=0$ \\
\hline & $\begin{array}{l}\mathrm{E}_{43} \text { the } \\
\text { extent to } \\
\text { which the } \\
\text { failure effect }\end{array}$ & $\begin{array}{l}\mathrm{E}_{431} \text { the } \\
\text { improvement } \\
\text { measures can } \\
\text { eliminate the }\end{array}$ & $\begin{array}{l}\text { After expert review, all the analyzed failure effects } \\
\text { have been improved, including hardware failure effects } \\
\text { and software and hardware comprehensive failure } \\
\text { effects }\end{array}$ & $\mathrm{E}_{431}=3$ \\
\hline & $\begin{array}{l}\text { has been } \\
\text { reduced }\end{array}$ & $\begin{array}{l}\text { failure effects } \\
\text { analyzed or } \\
\text { reduce the }\end{array}$ & $\begin{array}{l}\text { After expert review, all the hardware failure effects } \\
\text { have been improved, but the software and hardware } \\
\text { comprehensive failure effects have not been improved }\end{array}$ & $E_{431}=1$ \\
\hline & & $\begin{array}{l}\text { probability of } \\
\text { happening } \\
\text { without }\end{array}$ & $\begin{array}{l}\text { After expert review, some hardware failure effects have } \\
\text { been improved, but software and hardware } \\
\text { comprehensive failure effects have not been improved }\end{array}$ & $\mathrm{E}_{431}=0.6$ \\
\hline & & $\begin{array}{l}\text { introducing new } \\
\text { failures }\end{array}$ & $\begin{array}{l}\text { After expert review, a large number of hardware failure } \\
\text { effects and software and hardware comprehensive } \\
\text { failure effects have not been improved }\end{array}$ & $\mathrm{E}_{431}=0$ \\
\hline
\end{tabular}

Using the evaluation criteria established in Tab. $1, \mathrm{E}_{1} \sim \mathrm{E}_{4}$ can be evaluated, and then the evaluation of the FMEA application effect can be completed. The specific method is as follows, 
Firstly, according to the evaluation criteria given in Tab. 1, the degree of failure mode cognition, cause cognition, effect cognition and the effectiveness of improvement measures of FMEA are evaluated to determine the values of $E_{1} \sim E_{4}$. In Tab. 1, several evaluation points are given for each effect factor; moreover, corresponding evaluation requirements are given for each evaluation point. To facilitate the expert to make judgments, the scoring items are refined according to the evaluation requirements. For each item (the $\mathrm{k}^{\text {th }}$ evaluation requirement of the $\mathrm{j}^{\text {th }}$ evaluation point of the $\mathrm{i}^{\text {th }}$ effect factor), $\mathrm{E}_{\mathrm{ijk}}$, the experts give a score of 3,1 , 0.6 , or 0 according to the degree of compliance between the evaluation object and requirements. After collecting the expert scoring results, determine the values of $E_{1} \sim E_{4}$ through equations (6) and (7),

$$
\begin{gathered}
E_{i j}=\left(1 / n_{k}\right) \sum_{k=1}^{n_{k}}\left(E_{i j k} / 3\right) \\
E_{i}=\left(1 / n_{j}\right) \sum_{j=1}^{n_{j}} E_{i j}
\end{gathered}
$$

where, $n_{k}$ is the number of evaluation requirements included in the $j^{\text {th }}$ evaluation point of the $i^{\text {th }}$ effect factor; $n_{j}$ is the number of evaluation points included in the $i^{\text {th }}$ effect factor.

Secondly, the value of $\mathrm{E}$ is finally determined by considering the comprehensive effect of the degree of failure mode cognition, cause cognition, effect cognition, and the effectiveness of the improvement measures.

Equation (8) is used to characterize the comprehensive effect of $E_{1} \sim E_{4}$ on $E$. The value of $E$ can be determined to complete the evaluation of the effect of FMEA through equation (8),

$$
E=E_{4} \cdot \sum_{i=1}^{3}\left(\omega_{i} \cdot E_{i}\right)
$$

where, $\omega_{i}$ represents the weight occupied by $E_{i}$. It is obviously that, $0 \leq \omega_{i} \leq 1$ and $\sum_{i=1}^{3} \omega_{i}=1$. Here, assume that the contributions of the degree of failure mode cognition, the degree of failure cause cognition, and the degree of failure effect cognition are the same. Thus, $\omega_{1}=\omega_{2}=\omega_{3}=1 / 3$. It can also be seen that when $\mathrm{E}_{4}=0$, then, $\mathrm{E}=0$, i.e., if only FMEA is carried out without corresponding design improvement, such work is not meaningful for improving the reliability of system.

\subsection{The Evaluation Method of S/HCRT Application Effect}

The TS-based failure is both time and space dependent, resulting from the dual effects of stress and operation. Thus, it is necessary to adopt the mode of "reliability test + software test" ${ }^{[15]}$ for S/HCRT. This paper chooses reliability demonstration test (RDT) as the test type, which is generally performed on a higherlevel system to fully evaluate the condition of interface and improve the authenticity of test. The timing of this type of test also meets the prerequisites for detecting the TS-based failures.

The test process needs to select some failure types from the existing TS-based failure type set to constitute the set for test verification. This paper selects temperature failure, vibration failure and electricity failure. Moreover, the instances corresponding to the failure types in the set are given. And the stress levels of various types of stresses corresponding to the failure instances are given. The evaluation indexes of S/HCRT in this paper include the quality of test mode, test implementation, and test results. The evaluation process is shown in Fig. 2. The quality measurement level can be obtained and the specific process refers to the next section. Here, $\mathrm{T}$ is defined to characterize the application effect of the S/HCRT. Regulation: The larger $\mathrm{T}$, the better the application effect, and $T \in[0,1]$. The corresponding relationship between the test quality level and test application effect (EU factor value) is, Excellent-0.9; Good-0.8; Average-0.6; Poor-0.1.

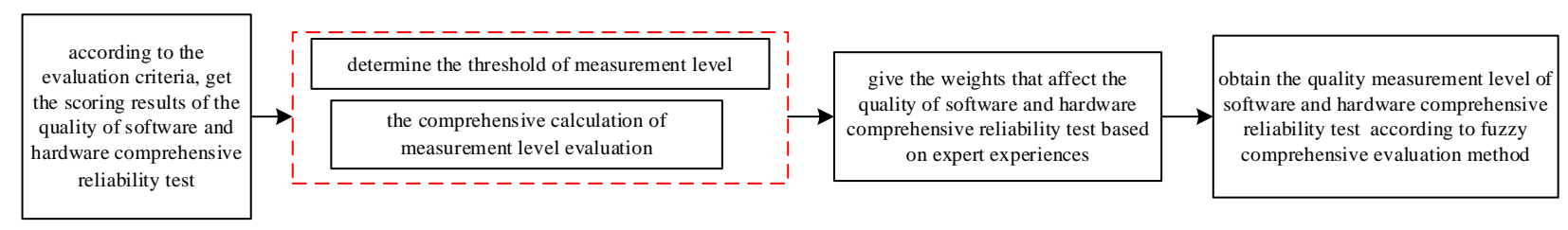

Fig. 2: The quality evaluation process of S/HCRT

\subsection{The Calculation of Eu Factor}

This paper considers the following factors that affect the EU, the EU related to the FMEA, and the EU related to the S/HCRT. Thus, the $\alpha_{e}$ is determined by the E and T. From the literature [13], $\alpha_{e} \in[0,+\infty)$, $\alpha_{e}=0, \alpha_{e}=+\infty$ represents the state of minimum and maximum EU, respectively. In this paper, the relationship between the $\alpha_{e}$ and $\mathrm{E}$ and $\mathrm{T}$ is described as, 


$$
\alpha_{\mathrm{e}}=\mathrm{d} /(\beta * \mathrm{E}+\gamma * \mathrm{~T})^{2}
$$

where, $\mathrm{d}$ is a proportional constant, usually $\mathrm{d}=0.5^{[16]} \cdot \beta$ and $\gamma$ are two proportionality coefficients, deriving from experience. Take 0.65 and 0.35 respectively.

\section{Application case}

In this section, the subsystem of a S/HIS is selected as the experimental object for application case. The subsystem contains temperature sensors and related software. The simulation modeling of the experimental object yields a DM $\mathrm{M}_{\text {design }}=0.0254$ and an AU factor $\alpha_{a}=0.4538$ according to the method proposed in [16]. The calculation process of the EU factor is given below, and the system BR value is further given.

\subsection{Determine the EU factor}

1) The calculation of the EU factor related to FMEA

Three experts were invited to evaluate the FMEA application effect of the system based on the system's FMEA report according to the evaluation criteria in Tab. 1. Substituting the evaluation results into equation (8), the evaluation results are shown in Tab. 2.

Table. 2 The application effect evaluation of a system

\begin{tabular}{|c|c|c|c|}
\hline Effect factor & Expert A & Expert B & Expert C \\
\hline the degree of failure mode cognition & 0.7 & 0.8 & 0.7 \\
\hline the degree of failure cause cognition & 0.8 & 0.8 & 0.7 \\
\hline the degree of failure effect cognition & 0.7 & 0.7 & 0.6 \\
\hline $\begin{array}{c}\text { the effectiveness of improvement } \\
\text { measures }\end{array}$ & 0.9 & 0.8 & 0.9 \\
\hline $\begin{array}{c}\text { scoring results } \\
\text { ofing }\end{array}$ & 0.66 & 0.61 & 0.60 \\
\hline
\end{tabular}

The average value of results of the three experts was used as the final score, $E=\left(E_{A}+E_{B}+E_{C}\right) / 3=0.62$.

2) The calculation of the EU factor related to S/HCRT

Set the value range of each level, poor(0.0,0.8), average(0.8,0.9), $\operatorname{good}(0.9,0.95)$, excellent $(0.95,1.0)$. Acquire that, $\mathrm{C}_{1}=0.4, \mathrm{C}_{2}=0.85, \mathrm{C}_{3}=0.925, \mathrm{C}_{4}=0.975$. Substituting them into the equation,

$$
\begin{aligned}
& v_{1}=0 \leq r \leq v_{2}=0.8 A_{2}(r)= \begin{cases}1 & v_{2}=0.8 \leq r \leq v_{3}=0.9 \\
\left(r-c_{1}\right) /\left(v_{2}-c_{1}\right)=(r-0.4) / 0.4 & c_{1}=0.4<r<v_{2}=0.8\end{cases} \\
& A_{1}(r)=\left\{\begin{array}{ll}
\left(r-c_{2}\right) /\left(v_{2}-c_{2}\right)=(0.85-r) / 0.05 & 0.8<r<0.85 \\
0 & \text { other }
\end{array} A_{2}(r)= \begin{cases}\left(r-c_{1}\right) /\left(v_{2}-c_{1}\right)=(r-0.4) / 0.4 & c_{1}=0.4<r<v_{2}=0.8 \\
\left(r-c_{3}\right) /\left(v_{3}-c_{3}\right)=(0.925-r) / 0.025 & v_{3}=0.9<r<c_{3}=0.925 \\
0 & \text { other }\end{cases} \right.
\end{aligned}
$$

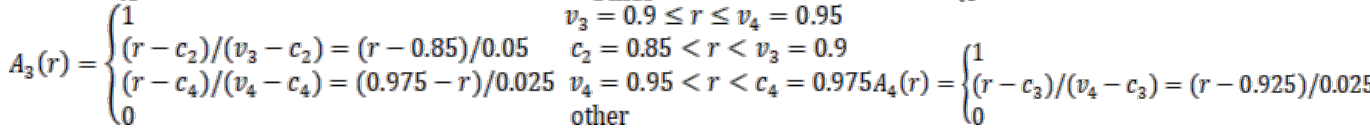

$$
\begin{aligned}
& v_{4}=0.95 \leq r \leq v_{5}=1.0 \\
& c_{3}=0.925<r<v_{4}=0.95
\end{aligned}
$$

Assume that there are $\mathrm{M}$ experts, and the $\mathrm{K}^{\text {th }}$ expert's qualitative score of its level according to the calculated value of the measurement $\mathrm{u}_{\mathrm{i}}$ is recorded as $\mathrm{r}(\mathrm{i}, \mathrm{k})$. A total of $\mathrm{M}$ scoring results is obtained, and the algebraic average value could be used as the comprehensive evaluation value for measuring the $\mathrm{u}_{\mathrm{i}}$ level, and recorded as, $R(i)=(1 / M) \sum r(i, k)$. Substituting $\mathrm{R}(\mathrm{i})$ into the above membership function, the fuzzy comprehensive evaluation results of each metric are obtained. After normalizing the above results, an evaluation matrix is constructed. Three experts were invited to evaluate the application effect of the S/HCRT from the aspects of quality of test mode, test implementation, and test result. The results are shown in Tab. 3.

Table. 3 The application effect evaluation of the S/HCRT

\begin{tabular}{|c|c|c|c|}
\hline Measurement index & test mode quality & $\begin{array}{c}\text { test implementation } \\
\text { quality }\end{array}$ & test result quality \\
\hline Expert 1 & 0.8 & 0.8 & 0.9 \\
\hline Expert 2 & 0.8 & 0.7 & 0.8 \\
\hline Expert 3 & 0.9 & 0.9 & 0.9 \\
\hline
\end{tabular}

It shows that $\mathrm{R}_{1}=0.83, \mathrm{R}_{2}=0.80, \mathrm{R}_{3}=0.87$; thus, the degrees of membership of the above application effect level are, $R_{1}: A_{1}(r)=0.4, A_{2}(r)=1, A_{3}(r)=0, A_{4}(r)=0 ; R_{2}: A_{1}(r)=1, A_{2}(r)=1, A_{3}(r)=0, A_{4}(r)=0 ; R_{3}: A_{1}(r)=0$, $\mathrm{A}_{2}(\mathrm{r})=1, \mathrm{~A}_{3}(\mathrm{r})=0.4, \mathrm{~A}_{4}(\mathrm{r})=0$, i.e., $\mathrm{U}_{1}\left|\rightarrow(0.4,1,0,0), \mathrm{U}_{2}\right| \rightarrow(1,1,0,0), \mathrm{U}_{3} \mid \rightarrow(0,1,0.4,0)$. After normalization, $\mathrm{U}_{1}\left|\rightarrow(0.2857,0.7143,0,0), \mathrm{U}_{2}\right| \rightarrow(0.5,0.5,0,0), \mathrm{U}_{3} \mid \rightarrow(0,0.7143,0.2857,0)$. The evaluation matrix is as follows,

$$
R=\left[\begin{array}{ccll}
0.2857 & 0.7143 & 0 & 0 \\
0.5 & 0.5 & 0 & 0 \\
0 & 0.7143 & 0.2857 & 0
\end{array}\right]
$$

Assume that the three application effect level weights are all 1/3, then, the quality measurement level is obtained according to the equation in the fuzzy comprehensive evaluation method. 


$$
\begin{aligned}
R U(i) & =W \circ R=\left\{w_{i 1}, w_{i 2}, \cdots, w_{i n}\right\} \circ\left[\begin{array}{cccc}
r_{11}^{\prime} & r_{12}^{\prime} & r_{13}^{\prime} & r_{14}^{\prime} \\
r_{21}^{\prime} & r_{22}^{\prime} & r_{23}^{\prime} & r_{24}^{\prime} \\
\vdots & \vdots & \vdots & \vdots \\
r_{n 1}^{\prime} & r_{n 2}^{\prime} & r_{n 3}^{\prime} & r_{n 4}^{\prime}
\end{array}\right]=\left\{R U_{i}{ }^{1}, R U_{i}{ }^{2}, R U_{i}{ }^{3}, R U_{i}^{4}\right\} \\
& =\left[\begin{array}{lll}
1 / 3 & 1 / 3 & 1 / 3
\end{array}\right]\left[\begin{array}{ccccc}
0.2857 & 0.7143 & 0 & & 0 \\
0.5 & 0.5 & 0 & 0 \\
0 & 0.7143 & 0.2857 & 0
\end{array}\right]=\left[\begin{array}{llll}
0.2619 & 0.6429 & 0.0952 & 0
\end{array}\right]
\end{aligned}
$$

The significance of RU is, the degree of membership of fuzzy comprehensive evaluation of the quality level of the S/HCRT at the "poor”, “average”, "good” and “excellent” level are 0.2619, 0.6429, 0.0952 and 0, respectively. According to the principle of maximum membership, the quality level of evaluation object is "average”. According to the corresponding relationship in Tab. 3, the corresponding EU factor value is 0.6.

3) The calculation of comprehensive EU factor

Substituting $\mathrm{E}=0.62$ and $\mathrm{T}=0.6$ into equation $(9), \alpha_{e}=d /(\beta * E+\gamma * T)^{2}=1.3306$.

\subsection{The Calculation of System BR}

Substituting $\mathrm{M}_{\text {design }}=0.0254>0, \alpha_{a}=0.4538$ and $\alpha_{e}=1.3306$ into equation (1) and (2), the BR of the system can be obtained as follows, $R_{B}=\Phi\left(1 /\left(\alpha_{a}+\alpha_{e}\right)\right)=0.7124$. If the influence of EU is not considered, i.e., $\alpha_{e}=0$, the reliability of the system is, $R=\Phi\left(1 / \alpha_{a}\right)=\Phi(1 / 0.4538)=0.9862$. Comparing the calculation results, the BR considering the influence of EU is significantly lower than the BR not considering the influence of EU. The reason for this difference is, the effects of the system's FMEA and S/HCRT need to be further improved; therefore, the influence of EU on the system is significant. In all, in the design process of system, on one hand, it is necessary to control the influence of AU; and on the other hand, it is necessary to further improve the reliability work of FMEA, S/HCRT, etc. to continuously reduce the EU and improve system reliability.

\section{Conclusion}

The system reliability is determined by the DM, AU, and EU. Existing reliability measures ignore the impact of EU. This paper proposed a calculation method of EU factor of S/HIS based on FMEA application effect and S/HCRT application effect. Furthermore, a BR evaluation method with comprehensive consideration of the DM, AU and EU was presented. Finally, the proposed method was demonstrated and verified through application case. The results show that the existence of EU will reduce people's trust in "system reliability". Thus, in the system design process, the reliability design goal should be achieved by continuously reducing the EU and controlling the AU. The FMEA and S/HCRT are just two of the common reliability engineering activities that can reduce the EU. Subsequent research can also consider integrating other engineering activities that can reduce EU to further improve the method for determining the EU factor.

\section{Acknowledgment}

This work was supported by the National Key Research and Development Program of China under Grant 2019YFC0118800. And this work was supported by Dr. Yiqiang Chen and Dr. Zhenwei Zhou, and I would like to express my sincere thanks.

\section{References}

[1] Matthias Hölzl, et al. Engineering of software-intensive systems: state of the art and research challenges, softwareintensive systems and new computing paradigms lecture notes in computer science, volume 5380, 2008, pp: 1-44.

[2] Purwantoro Y., et al. Decomposition technique for integrated dependability evaluation of hardware-software systems using stochastic Activity Networks. The 25th EUROMICRO, 1999: 142-145.

[3] Boyd M. A., et al. Developing integrated hardware-software reliability models: difficulties and issues. In Proceedings of Digital Avionics Systems Conference, 1995: 193 - 198.

[4] Jinhee Park, et al. An embedded software reliability model with consideration of hardware related software failures. IEEE Sixth International Conference on Software Security and Reliability, 2012: 207-214.

[5] Schenidewind N. F., Computer, network, software, and hardware engineering with applications. John Wiley \& Sons, 2012: 315-334.

[6] Cano J., et al. Reliability forecasting in complex hardware/software systems. ARES, 2006: 1-5. 
[7] Teng Xiaolin, et al. Reliability modeling of hardware and software interactions, and its applications. IEEE Transactions on Reliability, 2006, 55(4): 571-578.

[8] Upadhyayula K., et al. Physics-of-failure guidelines for accelerated qualification of electronic systems. Quality and Reliability Engineering International, 1998, 14(6): 433-447.

[9] Apostolakis G., The concept of probability in safety assessments of technological systems. Science, 1990, 250(4986): 1359-1364.

[10] Paté-Cornell M E. Uncertainties in risk analysis: six levels of treatment. Reliability Engineering \& Systems Safety, 1996, 54(2/3): 95-111.

[11] Eldred M S, et al. Mixed aleatory-epistemic uncertainty quantification with stochastic expansions and optimization-based interval estimation. Reliability Engineering \& System Safety, 2011, 96(9): 1092-1113.

[12] Zeng Z G, et al. Belief reliability: a new metrics for products' reliability. Fuzzy Optimization and Decision Making, 2013, 12(1), 15-27.

[13] Zeng Z G, et al. Measuring reliability during product development considering aleatory and epistemic uncertainty. proc. of the reliability and maintainability symposium, 2015: 1-6.

[14] IEC 60812, Failure modes and effects analysis (FMEA and FMECA), Edition 3.0, 2018.

[15] Xuan Hu, et al. The Time/State-based Software-Intensive Systems Failure Mode Researches, $7^{\text {th }}$ International Conference on Software Security and Reliability Companion, 2013: 116-124.

[16] Fan Mengfei, et al. An approach to measure reliability based on belief reliability, Systems Engineering and Electronics, 2015, 37(11), pp. 2648-2653.

[17] Hu Xuan, The complex system reliability comprehensive experiment and analysis method researches, SCUT/MIIT CEPREI Joint recruitment of postdoctoral research report, 2014.11.

[18] Li Haifeng. Research on Qualitative Evaluation Technology of Software Reliability. Beijing: Beihang University, 2006. 